\title{
nature
}

12 February 1998 Volume 391 Issue no 6668

Time to withdraw an

undesirable privilege?

The practice by which some researchers restrict access to published data for a year has hitherto been accepted. Nature and Science are collaborating to investigate whether that acceptance should cease.

A principled editorial policy, implemented with rigour, can lose a journal some excellent papers to other journals that are more lax. What is more, journals are in a poor position to wag the dog of community behaviour. Nevertheless, there are occasions when they can have a significant influence, especially if competitiveness can be sidestepped. One such occasion may be approaching in respect of the vexed issue of the availability, on publication, of crystallographic coordinates of biomolecular structures.

Most researchers believe that, once a piece of science has been published, the methods and materials on which it is based as well as the results themselves should be publicly available, immediately. Many structural biologists disagree. For them, it is a common practice, on publication, to deposit crystallographic atomic coordinates in a repository such as the protein database at Brookhaven National Laboratory, but to keep them inaccessible for a year.

In this context, Nature's policy is to publish when (and only when) a database accession number is supplied, but to accept the principle of the one-year embargo. But that acceptance is increasingly reluctant. As the use of structural data becomes ever greater across biology, that practice is ever more frustrating to the progress of science, not to say offensive to the broader community.

One obstacle to change is the claim by some structural biologists (see Nature Structural Biology 5, 83; 1998) that researchers are owed the breathing space of a one-year hold to exploit results that have been obtained by dint of investment of many months of work, with the substantial risk that the analysis will prove unsuccessful. Researchers in other fields may well view such a claim as special pleading. Another obstacle is the knowledge that such data may not be patentable (although that possibility is being investigated by lawyers), and also that industry, with major quantities of information up its sleeve that non-industrial researchers can make good use of, will refuse to collaborate if immediate openness is required.

The extent to which all of these considerations should determine policy is highly debatable. Nevertheless, they clearly win the argument within the International Union of Crystallographers, whose continuing support for the one-year hold has considerable influence within the structural biological community.

Nature is a service provider. If the journal singlehandedly insists on immediate public access, and enforces that as rigorously as it does, for example, for geneticists, it could lose some excellent papers - or, to put it less selfishly, could cease to be considered as an appropriate service provider. But whose interests are we serving? It seems that increasingly, in accepting the one-year hold, we are serving industry at the expense of science.

We believe that the best way forward is to consult but also to minimize the use of such policy as a competitive weapon between journals. Accordingly, Nature and Science have agreed to collaborate in consulting the community and, potentially, reaching a simultaneous and mutually consistent decision on any change of policy. (Other journals are also being consulted.) Both journals are encouraging readers to express their opinions via a survey being conducted via the website of Nature Structural Biology (http://structbio.nature.com). Either by that means or by correspondence(corres@nature.com),we would welcome readers' opinions.

\section{Stockpiler's suppression}

\section{Is the US Department of Energy abusing its monopoly of information on nuclear weapons to stifle argument?}

$\mathrm{O}$ ne reason why the United States elected to place its nuclear weapons technology under the control of a civilian agency was that issues surrounding the weapons were seen to be too important to be left to a military clique. The resulting system does not allow information on nuclear weapons to pour out into the public domain. Important technical information is kept secret - but it is nonetheless made available to a fairly wide circle of security-cleared experts, who are able to use it to inform a relatively open public debate on weapons policy.

There are disquieting signs that the Department of Energy (DOE) is failing to adhere to this mode of operation, as it singlemindedly pursues its intended policy of science-based stockpile stewardship a programme developed to maintain the viability of existing US nuclear weapons after the proposed implementation of the Comprehensive Test Ban Treaty.

Ray Kidder, a weapons designer with a long and influential track record in both theoretical physics and nuclear weapons policy, has been denied the opportunity to help the Arms Control and Disarma- ment Agency (ACDA) to assess maintenance options for nuclear weapons (see page 622). The denial came after the energy department declined to give him the necessary access to classified material. ACDA is not strong at the moment - it is about to be absorbed by the State Department - and it has not been able to stand up to DOE. The National Security Council may also have intervened to secure Kidder's exclusion.

But concern about the closed nature of the debate on stockpile stewardship does not stop with the treatment of Ray Kidder, who made his critical views on the issue known in Nature last year (386, $645 ; 1997)$. The formulation of the entire policy during the Clinton administration has been overly constrained by political concerns. No-one outside DOE has been allowed to compare stewardship - a crafty if expensive compromise solution - with alternative approaches, such as the remanufacturing option advocated by Kidder. Congress should insist on such a comparison, as it considers the administration's extravagant request of $\$ 4.5$ billion for stockpile stewardship in 1999. 